\title{
Mineralogical Characterization Applied to Iron Ore Tailings from the Desliming Stage with Emphasis on Quantitative Electron Microscopy (QEM)
}

\author{
Arley Henrique de Souza ${ }^{a *}$ (1), Fernando Leopoldo von Krüger ${ }^{b}$ (1), \\ Fernando Gabriel da Silva Araújo ${ }^{a}$ (1), Jefferson Januário Mendes ${ }^{c}$ (1) \\ ${ }^{a}$ Universidade Federal de Ouro Preto, Ouro Preto, MG, Brasil. \\ ${ }^{b}$ Fundação Gorceix, Ouro Preto, MG, Brasil. \\ 'Instituto Federal de Educação, Ciência e Tecnologia de Minas Gerais, Congonhas, MG, Brasil.
}

Received: December 16, 2019; Revised: August 25, 2020; Accepted: October 31, 2020

\begin{abstract}
The search for alternatives that minimize the generation of tailings and enable their reuse, leads to characterization studies with the objective of a better understanding of the physical, chemical and mineralogical properties of iron ore tailings. The increase in demand for high-quality ore overlapping ore extraction with increasingly lower iron concentration levels, is part of the challenge of mineral exploitation. In view of the aforementioned needs, a more detailed characterization of the tailings contributes to the improvement of the mineral processing stage and the reuse of the generated tailings. To this end, an analysis of the characteristics of the tailings was carried out through physical, chemical and mineralogical characterization, with emphasis on quantitative electron microscopy - QEM. The tests revealed that the predominant phases are hematite and quartz and, to a lesser extent, goethite, gibbsite and kaolinite. As for the degree of release, hematite/magnetite has $88.13 \%$ of its particles totally free, $0.53 \%$ associated with quartz and $6.77 \%$ associated with goethite. The chemical composition is $32.29 \% \mathrm{Fe}, 47.92 \% \mathrm{SiO}_{2}, 2.76 \% \mathrm{Al}_{2} \mathrm{O}_{3}$, and $2.14 \%$ PPI. In this scenario, mineralogical characterization, as a main component of geometallurgy, makes it possible to propose alternatives that improve the ore beneficiation process and the reuse of tailings.
\end{abstract}

Keywords: Iron ore, mineralogical characterization, quantitative electron microscopy.

\section{Introduction}

Iron ore is one of the main exploited mineral resources in the world and it would be no different in Brazil. It is the second metal in abundance in the lithosphere, covering approximately $4.2 \%$ of it. It was, is and will be part of the countries' industrialization process, being the main raw material for the manufacture of steel, being directly linked to the development of the world market and economy ${ }^{1,2}$.

However, the gradual depletion of high-grade iron ore deposits, leads to a critical scenario in the mining industry, encouraging the use of low-iron ore, process fines and, above all, tailings generated in the mineral processing ${ }^{3}$.

It is worth noting that the impoverishment of deposits and the levels of mined and processed ores directly impacts the greater generation of tailings resulting from the process. According to the Institute of Applied Economic Research - IPEA ${ }^{4}$, it is estimated that in Brazil, during the period between 2010-2030, the projection of tailings resulting from the processing of iron ore will account for approximately $41.38 \%$ of the total of tailings generated by the country's mining companies.

It is important to note that each deposit has unique mineralogical characteristics, thus requiring a specific type of

*e-mail: arley_s@yahoo.com.br processing to obtain each product. The choice of beneficiation stages depends on the nature of the gangue present in the ore and its association with the mineral of economic value, so it is necessary to carry out a geometallurgical study, combining different characterization techniques, which will allow a better perception of the different characteristics mineralogical properties of the ore and its influence on the processing of generated tailings $\mathrm{s}^{3,5,6}$.

The steps used in the processing of raw ore - ROM, are: crushing and grinding, screening, classification, concentration, dewatering and disposal of tailings ${ }^{7}$. The steps commonly used in the concentration and treatment of tailings in the process are: classifying spirals, hydrocyclones, magnetic concentration and flotation ${ }^{8}$. The definition of a model that encompasses information, both on the ore and on the generated tailings, has the capacity to optimize the beneficiation and concentration operations.

Previously presented works ${ }^{3,6,9}$, demonstrated that the combined study of different characterization techniques, addressed by physical, chemical and mineralogical characterization tests, offers a better perception of the different mineralogical attributes of iron ore and its relationship with the processing steps $^{6}$. From the results generated, it is possible to discuss and propose different processing methods, leading to changes in the processing steps already used. 
Through geometallurgy, as a planning and process management tool, the inclusion of the information obtained by the characterization converges to the optimization of mine planning, to the efficiency of the beneficiation model and, therefore, to the reduction of the generation of tailings, providing a better use of the mineral resources of a deposit.

The work is therefore focused on the need for characterization, which is a source of mineralogical information on the characteristics and properties of the tailings. This study is motivated by the search for alternatives that mitigate the generation of tailings, as well as their destination for dams. Thus, the characterization work is of paramount importance for the future of mining, since the comprehensive use of tailings is vital for the conservation of non-renewable natural resources, guaranteeing the sustainable development of the mining sector ${ }^{3}$.

\section{Materials and Methods}

The sample directed to the work comes from a mine in the region of the iron quadrilateral in the state of Minas Gerais. Sample collection was performed at the hydrocyclones exit point (overflow), prior to directing the tailings to the thickener. The operation took place during a day of production of the mine, and the collections were divided into intervals of 1 hour during the 3 shifts of operation. The increments were collected and packed in 10 plastic drums of $20 \mathrm{~kg}$ each, totalling $200 \mathrm{~kg}$ of pulp, which were sent to the Department of Research and Continuing Education - DEPEC - Gorceix Foundation and later to the NanoLab Laboratory of the Metallurgical Mining Center - CMM - REDEMAT - UFOP and the Department of Mining Engineering - DEMIN - UFMG.

The determination of the particle size distribution of the tailings particles was performed using the light scattering technique, using laser particle size analysis using the Malvern Instruments equipment, model Mastersizer 2000. The sample was dispersed in water and the measurement range used was from 0.02 to $2000 \mu \mathrm{m}$ to obtain the size distribution curve of the tailings. For this test, the sample was dispersed in an aqueous solution, homogenized by propeller impeller with the aid of ultrasound excitation.

The determination of the sample density was performed using a helium pycnometer, model Multipycnometer, from Quantachrome Instruments, with three purging cycles in natural sample. The determination of the volume of solids by varying the gas pressure in a chamber of known volume was performed using helium, as it is light, inert and monoatomic. The tests were carried out at a water temperature of $20^{\circ} \mathrm{C}$, the washing time was 5 minutes and the elutriation time was 10 minutes. The tested fractions were previously oven dried at $80^{\circ} \mathrm{C}$.

The determination of magnetic susceptibility was carried out by means of magnetic concentration. A quantity of the sample was selected to be subjected to the concentration test by scanning with magnetic field variation. The INBRAS model WHC magnetic separator was used, with a magnetic field variation from 0.2 to 1.5 teslas.

The quantitative chemical analysis of the sample was performed by X-ray fluorescence in the Panalytical Zetium model equipment, using the technique of fused tablets, in the RO-XRF calibration, referring to the analysis with iron ore and rock standards. The sample was pulverized in an orbital mill and prepared to be pressed into tablets for the identification of the main elements, operating at a voltage of $40 \mathrm{kV}$ and current of $60 \mathrm{~mA}$ with a counting time of $12 \mathrm{~s}$, the standard deviation of the method is $0.50 \%$. The determination of iron oxide $(\mathrm{FeO})$ was performed by volumetry and the ignition loss value (PPI) was analyzed by gravimetry at $1000^{\circ} \mathrm{C}$ for 1 hour.

The qualitative analysis of the mineral phases present in the sample was carried out by the X-ray diffraction technique. Through the determination of the crystalline structure it was possible to identify the minerals and the phases present. In preparing the sample, it was pulverized, pressed by hand on a glass slide and inserted into the Philips-Panalytical X-ray diffractometer, model PW 1710, which has a copper tube (anode), therefore, using copper $\mathrm{K} \alpha$ radiation $(\lambda=1.5406 \AA)$. The measurements were made with the programming covering the scanning angle from $3^{\circ}$ to $90^{\circ}$ degrees, with a counting time of 0.3 seconds and step of $0.060^{\circ} 2 \theta$, the standard deviation depends on the crystallinity of the phase and can vary from 1 to $2 \%$. For the calibration of the X-ray diffractometer, a pure metallic Si tablet was used, where the main peak is adjusted, which has the maximum intensity with the expected $2 \theta$ position, according to the ICDD standard for this phase.

The X-ray diffraction depends on some variables, for which the quality adjustment is made by evaluating the parameters: Rwp - weighted profile factor and GOF - goodness of fit (less than 2). In this case, the Rwp is less than $10 \%$ and the GOF is between 1 and $2 \%$, both values are standardized in order to obtain satisfactory results.

The quantitative analysis of the mineral phases obtained by X-ray diffraction was associated with the analysis of diffraction with the Rietveld structural refinement method, semi-quantitatively determining the sample's mineralogical composition, with a standard deviation of $5 \%$. The Rietveld method allows the refinement of complex crystalline structures with precision, working with quantifications by comparing the real spectrum of the sample, with simulated theoretical spectra, based on hypothetical mixtures of the phases ${ }^{10}$.

The Rietveld method consists of the point-to-point adjustment of all intensities obtained experimentally ( $\left.\mathrm{y}_{\mathrm{i}-\mathrm{obtained}}\right)$ with the calculated intensities ( $\mathrm{y}_{\mathrm{i} \text {-calculated }}$, based on a determined crystalline model (standard), diffraction optical effects, instrumental factors and other characteristics of the sample. The parameters included in the model are refined using the least squares method in order to minimize the residual Sy (residual function). The intensities of the diffraction peaks are directly proportional to the occurrence of the crystals of a given crystalline phase, for whose identification the relative intensities are taken into account when compared to the standards.

Quantitative mineralogical analysis was performed using the quantitative electron microscopy technique - QEM, using the TESCAN MIRA3 LMH - FEG model, with an energy beam corresponding to $25 \mathrm{kV}$, with probe current equal to $5.32 \mathrm{nA}$, with beam intensity equal to $18.67 \mathrm{eV}$ and $\mathrm{X}$-ray events per pixel corresponding to 1000 . The sample was embedded in epoxy resin, in the form of $30 \mathrm{~mm}$ diameter tablets, polished and covered with carbon film, and the analysis time for each tablet was in average of 90 minutes. The scanned volume corresponds to $6250000 \mu \mathrm{m}^{3}$, with the volume of the phases equal to $2389776 \mu \mathrm{m}^{3}$ and classified volume of $95.69 \%$. 
The technique associates integrated automated systems of scanning electron microscopy and X-ray dispersive energy spectrometer (SEM-EDS), correlating pixel size equal to $3 \mu \mathrm{m}$ to the field size corresponding to $3000 \mu \mathrm{m}$ X $3000 \mu \mathrm{m}$, being analyzed 25 fields, in which the number of particles analyzed is equal to 190833 . Once the sample is inserted into the SEM, the control software Tescan GoIntegrated Mineral Analyzer - TIMA, analyzes, in an integrated manner, the minerals contained in the sample.

Quantitative electron microscopy - QEM, associated with SEM-EDS is an automated model that measures qualification and quantification measures of the minerals present in a given sample. Such measurements are possible from the association of secondary electron images, with the backscattered electrons (BSE) image and with the microanalysis of the X-ray dispersive energy spectrometer (EDS), for the mineralogical classification of each sample.

The image of the backscattered electrons (BSE) shows the grains with shades of gray the lighter the higher the average atomic numbers of the phases, which makes it possible to make a preliminary separation of the present phases.

An imaginary grid is superimposed on this image and, in each pixel of that grid, the characteristic X-ray spectrum is acquired, which in turn is compared with the standard spectra in the database, which correspond to a diversity of catalogued mineral species. When the spectrum acquired by the equipment, occasionally, coincides with the database spectrum, the mineral phase is identified and coloured, as shown in Figure 1. The elements are thus identified by the

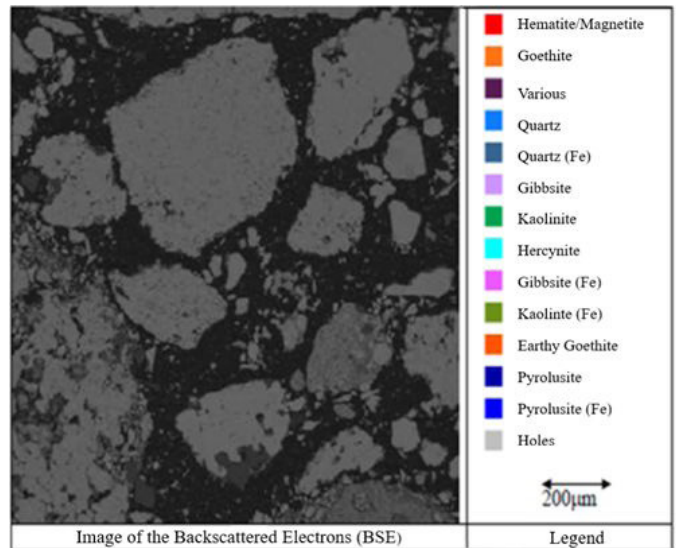

Figure 1. Stage of identification of mineral phases. positions of the peaks and the proportions are determined by the heights relative.

The phase map makes it possible to visualize the characteristics of the particles present in the sample, and they are analyzed following the classification premises that consider the main minerals frequently found in iron ores. It is worth mentioning that for all minerals a certain degree of contamination was admitted and, for gangue minerals, when the contamination by iron is greater, the suffix $(\mathrm{Fe})$ was used.

It is important to note that the hematite and magnetite minerals are not readily distinguishable by the technique, as they have the characteristic X-ray spectra very close, so that their sum is considered to obtain such results.

\section{Results and Discussion}

\subsection{Granulometry}

The granulometric distribution analysis was performed by laser granulometry, obtaining the results presented in Figure 2, results that indicate that the sample has a granulometric distribution with $\mathrm{D}_{50}$ equal to $51.35 \mu \mathrm{m}$, demonstrating that it is composed of fine material. It was also obtained as a result the determination of the specific surface of the sample, indicating that its value corresponds to $1980 \mathrm{~cm}^{2} / \mathrm{g}$, information that helps in the filtration steps, as it impacts on the pulp filtration unit rate.

It is important to highlight that granulometry plays an important role in the iron ore classification and beneficiation
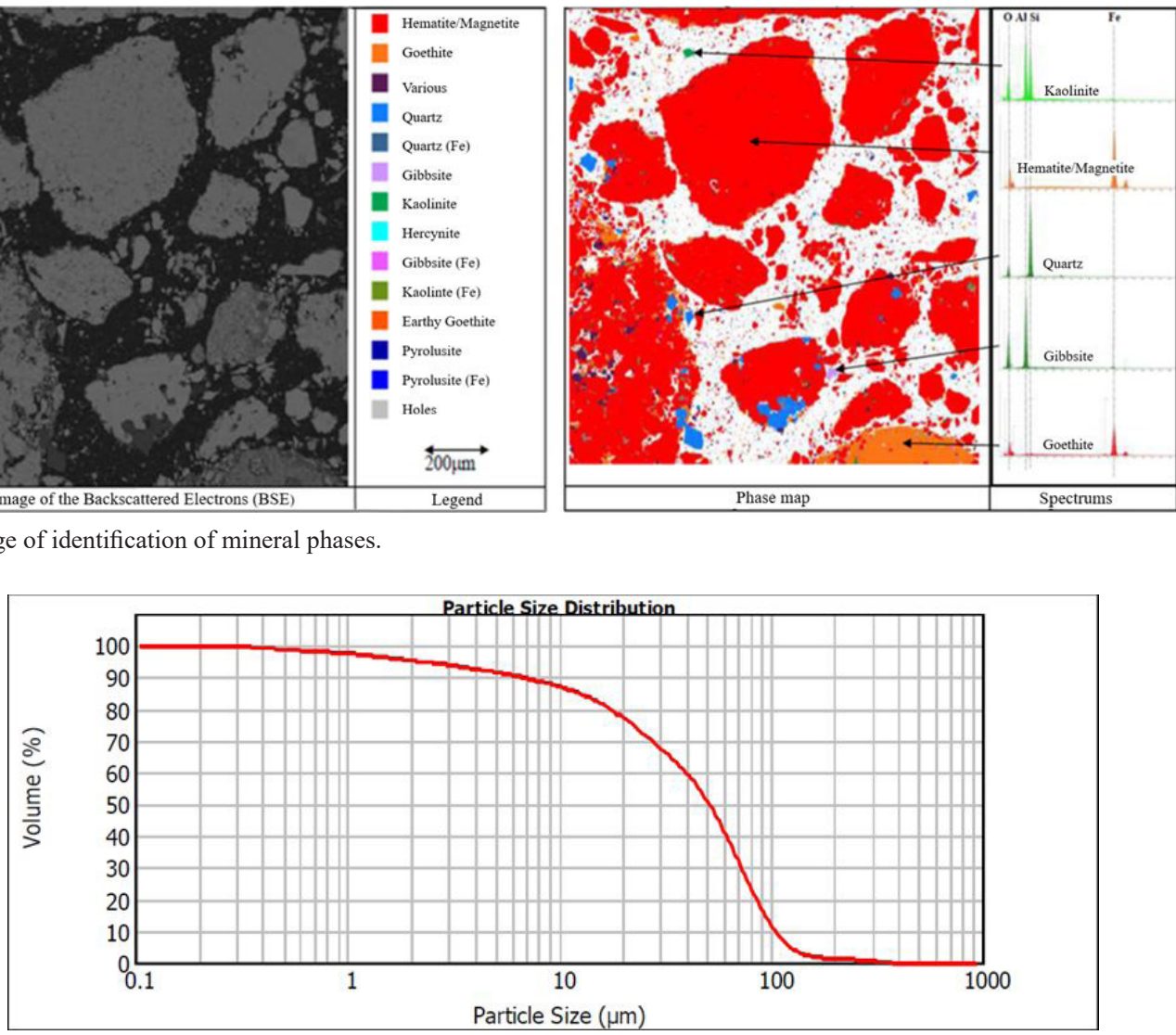

Figure 2. Particle size distribution by laser granulometry. 
process, such as determining the degree of ore release, the crushing and screening work ranges, the size distribution in the process feed, among others.

\subsection{Magnetic Density and Susceptibility}

The determination of the desliming tailings density was obtained by the helium pycnometer method, and the result found was $3.423 \mathrm{~g} / \mathrm{cm}^{3}$.

As for the magnetic susceptibility, the result of the concentration tests by scanning the applied magnetic field, made it possible to evaluate the behaviour of the material and see the percentage in retained mass. The fields in which there is a higher percentage of concentration are 0.6 and 1.2 teslas, it is observed that, of the sample volume, $47.20 \%$ was attracted by the applied fields and that $52.80 \%$ were repelled by these same fields. Thus, the possibility of magnetic concentration opens up in order to increase the rate of iron recovery in the tailings.

The analysis of density and magnetic susceptibility are fundamental for the separation or concentration steps in the processing of iron ore and in obtaining the mineral of interest.

\subsection{Chemical Composition}

The chemical analysis of the sample was obtained by $\mathrm{X}$-ray fluorescence, volumetry and gravimetry and the results are shown in Table 1, which indicates that the sample has $32.29 \%$ iron, having a high silica content with $47.92 \%$. The high alumina content of $2.76 \%$ indicates the presence of phyllosilicate minerals (kaolinite and gibbsite) and the PPI with a value equal to $2.14 \%$ indicates the presence of goethite.

\subsection{X-Ray Diffraction}

Figure 3 shows the diffractogram of the analyzed sample, qualitatively determining the mineralogical composition of the desliming tailings and their mineral phases, it is observed that the sample is dominated by the presence of quartz $\left(\mathrm{SiO}_{2}\right)$ and hematite $\left(\mathrm{Fe}_{2} \mathrm{O}_{3}\right)$, followed by the phases kaolinite $\left(\mathrm{Al}_{2} \mathrm{Si}_{2} \mathrm{O}_{5}(\mathrm{OH})_{4}\right)$, goethite $(\mathrm{FeO}(\mathrm{OH}))$ and gibbsite $\left(\mathrm{Al}(\mathrm{OH})_{3}\right)$. The main minerals that contain iron are hematite and goethite. The aluminium hydroxide mineral is identified as gibbsite, while silicate minerals are identified as kaolinite and quartz.

It is noteworthy that for the sample the presence of magnetite was not determined due to the percentage limit of detection of the device, that is, the percentage values of magnetite are below this limit, as well as the overlap of the magnetite peaks by the peaks of the hematite.

\subsection{Structural analysis by Rietveld}

The quantification, percentage by mass of the crystalline phases, was performed using the structural refinement Rietveld. The refinement analysis was performed for the sample and is shown in Table 2, revealing the mineralogical composition of the sample, in which the majority presence of quartz with

Table 1. Chemical composition of the desliming tailings sample.

\begin{tabular}{|c|c|c|c|c|c|c|c|c|c|c|c|c|c|c|}
\hline \multirow{3}{*}{$\begin{array}{c}\text { Desliming } \\
\text { Tailings }\end{array}$} & $\mathrm{Fe}$ & $\mathrm{SiO}_{2}$ & $\mathrm{AI}_{2} \mathrm{O}_{3}$ & $\mathrm{Mn}$ & $\mathrm{P}$ & $\mathrm{CaO}$ & $\mathrm{MgO}$ & $\mathrm{TiO}_{2}$ & $\mathrm{Na}_{2} \mathrm{O}$ & $\mathrm{K}_{2} \mathrm{O}$ & $\mathrm{Cr}_{2} \mathrm{O}_{3}$ & $\mathrm{FeO}$ & PPI & SUM \\
\hline & $\%$ & $\%$ & $\%$ & $\%$ & $\%$ & $\%$ & $\%$ & $\%$ & $\%$ & $\%$ & $\%$ & $\%$ & $\%$ & $\%$ \\
\hline & 32.29 & 47.92 & 2.76 & 0.21 & 0.041 & 0.03 & 0.07 & 0.27 & $<0.01$ & 0.04 & $<0.01$ & 0.14 & 2.14 & 99.76 \\
\hline
\end{tabular}

Table 2. Percentage by mass of crystalline phases present in the sample

\begin{tabular}{ccccccccc}
\hline \multirow{2}{*}{$\begin{array}{c}\text { Desliming } \\
\text { tailings }\end{array}$} & Hematite & Quartz & Magnetite & Kaolinite & Goethite & Gibbsite & Residue \\
\cline { 2 - 8 } & $\%$ & $\%$ & $\%$ & $\%$ & $\%$ & $\%$ & 0.2 & 0.291 \\
\hline
\end{tabular}

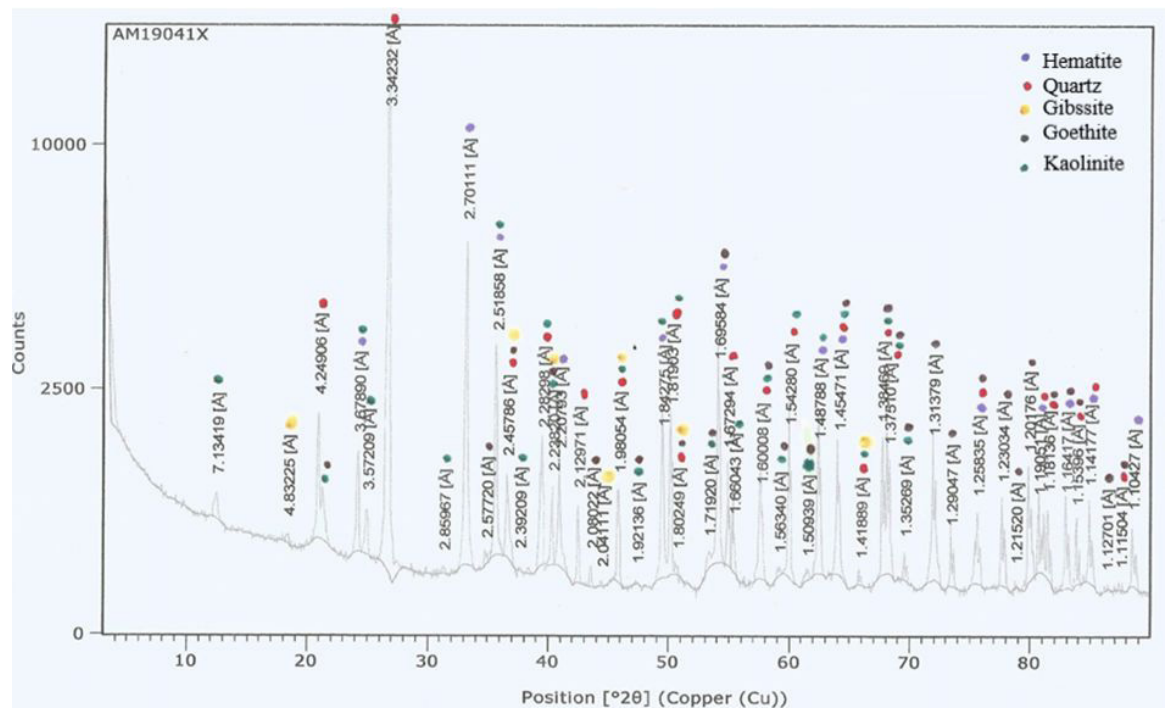

Figure 3. Diffractogram containing the main phases present in the desliming tailings. 
$56.60 \%$ and hematite with $30.20 \%$, followed by kaolinite with $10.40 \%$, goethite with $2.70 \%$ and gibbsite with $0.20 \%$.

In a purely explanatory character, without promoting the comparison between the techniques of quantitative electron microscopy - QEM, and Rietveld, there is a difference in the quantified percentages for the quartz phase. The quantification performed by Rietveld is a semi-quantitative analysis, as well as by quantitative electron microscopy - QEM, and considers only the crystalline phases identified by X-ray diffractometry, a method that, it is worth emphasizing, has a certain limit of detection that is not very accurate. With this, it may happen that the goethite is partially amorphized, and in this case the quantification is compromised, because it only took into account the crystalline fraction of this phase, sub-quantifying it, and the other phases would have their fractions increased. This situation clarifies the reason for the difference between the values detected by the different techniques mentioned above.

\subsection{Quantitative Electron Microscopy - QEM}

The analysis by quantitative electron microscopy - QEM allows the visualization of the characteristics of the particles present in the sample, through the image of the generated phase map. According to the image in Figure 4, the sample has quartz particles with larger and equiaxial sizes and particles of hematite/magnetite with smaller sizes and of different shapes, the other phases have very small sizes with different shapes.
The hematite and magnetite minerals are classified in a single phase, hematite/magnetite, due to the technical difficulties in distinguishing these minerals, given that, in addition to having similar brightness in the images of the Backscattered Electrons (BSE), they have spectra of close characteristic $\mathrm{X}$-rays detected by energy dispersion spectroscopy - EDS.

The graph in Figure 5 lists the mineralogical composition of the sample by quantitative electron microscopy - QEM, with the main phases present. It is worth mentioning that the minerals described as "unclassified" are those in which the phases did not find correspondence in the database.

It is observed that quartz, together with hematite/ magnetite, are the predominant minerals in the sample, respectively $39.20 \%$ and $37.48 \%$, with goethite as the tertiary phase, with a presence of $13.74 \%$. The unclassified phases represent $3.34 \%$ and the set of other phases present in the sample is responsible for $6.24 \%$ of the total.

The frequency of mineral phases by size ranges obtained by quantitative electron microscopy - QEM, is shown in the graph in Figure 6.

Most hematite/magnetite particles have sizes between $37 \mu \mathrm{m}$ and $6 \mu \mathrm{m}$, with $75.82 \%$ of their particles found in this range. Quartz particles are concentrated in the ranges above $26 \mu \mathrm{m}$, with $94.23 \%$ of their particles above this value. Goethite particles are concentrated in the ranges below $37 \mu \mathrm{m}$, with $85.67 \%$ of their particles below this value. The kaolinite particles are concentrated in the ranges below $37 \mu \mathrm{m}$ with $85.68 \%$ of their particles below this value. Most of the

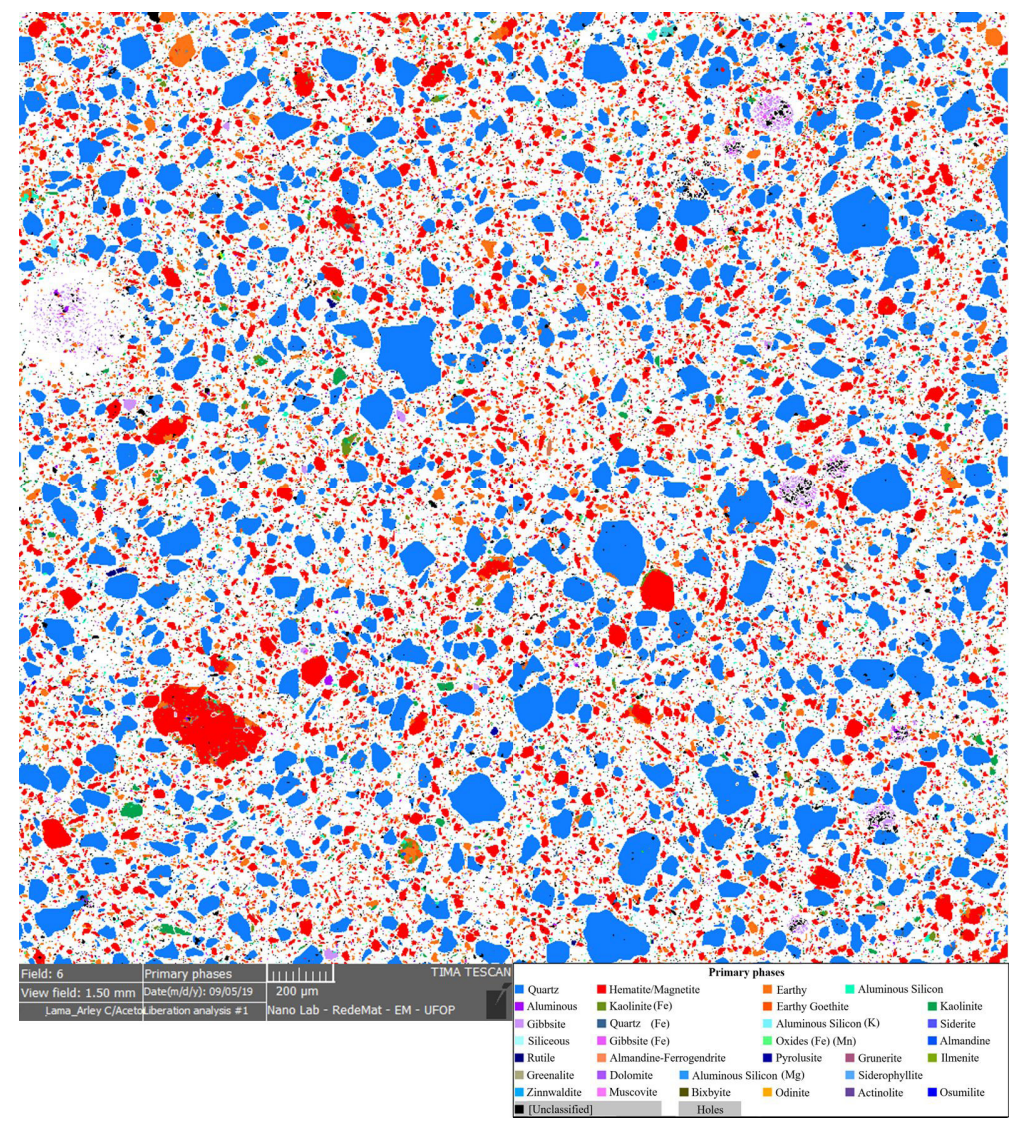

Figure 4. Phase map of the global sample. 


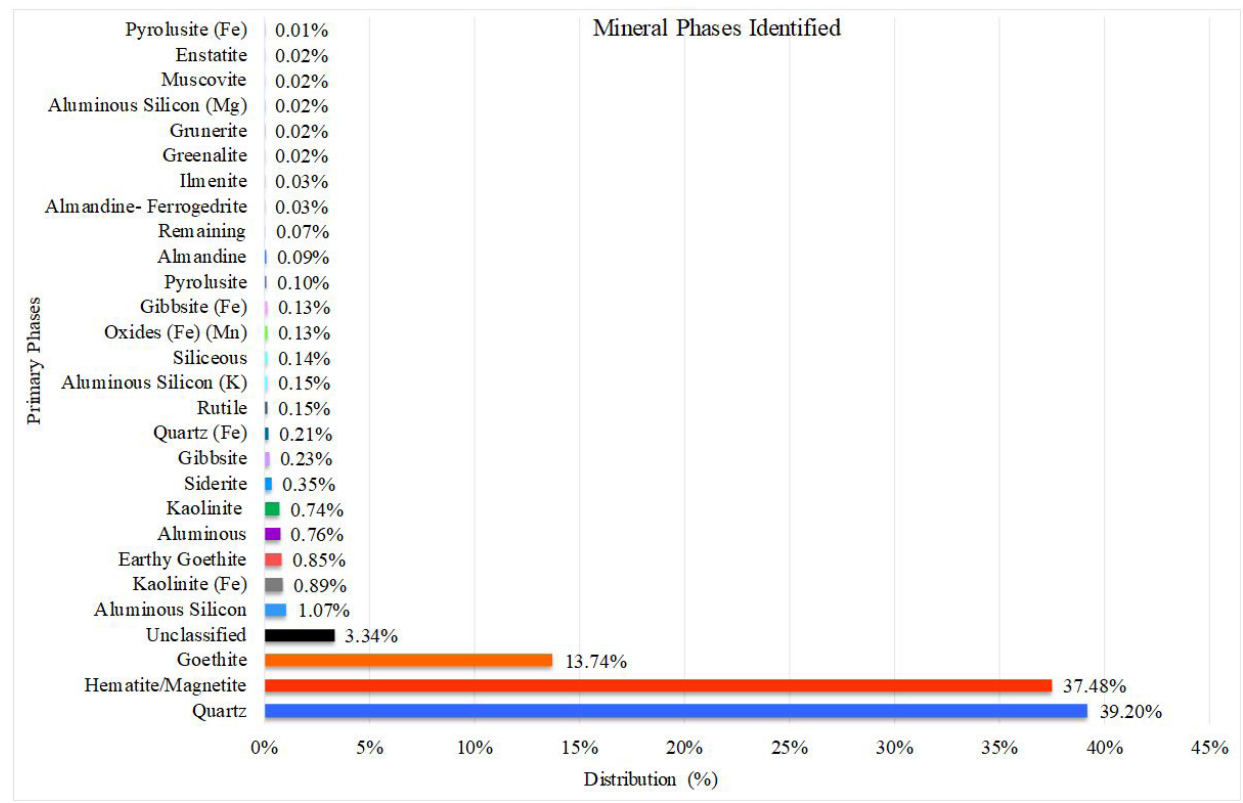

Figure 5. Mineral phases identified.

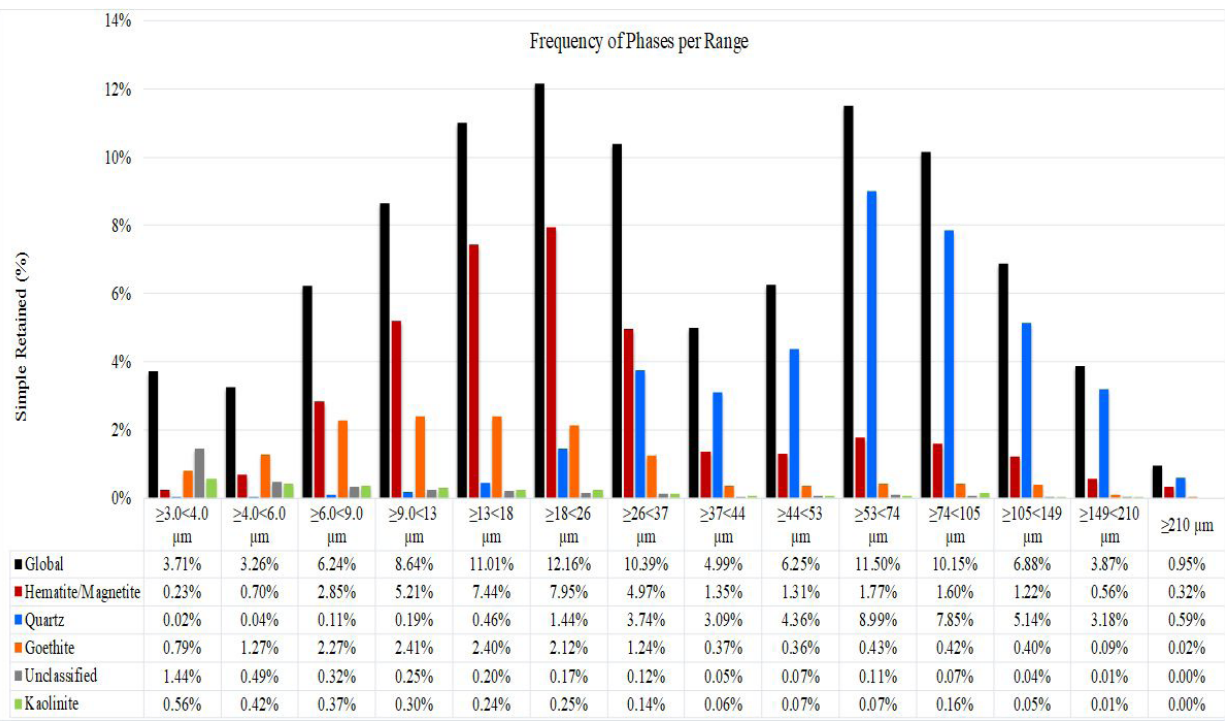

Figure 6. Frequency of mineral phases per range.

unclassified phases are made up of very fine particles. It is worth mentioning that the percentage of particles below $6 \mu \mathrm{m}$ represents $5.96 \%$ of the total of such particles.

According to Figure 7, for the four most abundant minerals, how much of its surface is free or how much is associated with other mineral phases.

Hematite/magnetite has $88.13 \%$ of its particles totally free, $0.53 \%$ associated with quartz and $6.77 \%$ associated with goethite. Quartz has $89.82 \%$ of its particles totally free, $0.69 \%$ associated with hematite/magnetite and $2.32 \%$ associated with goethite. Goethite has $82.45 \%$ of its particles totally free, $1.79 \%$ associated with quartz and $7.95 \%$ associated with hematite/magnetite. Kaolinite has $83.33 \%$ of its particles totally free, and $4.44 \%$ associated with goethite.

\subsection{Implications for Theory and Practice}

Currently, treating poorer iron ores with low levels has been a challenge for mining, and effectively separating the ore of interest from the tailings is a concern. The size of the particles and the degree of release impact the efficiency of the separation and concentration steps in mineral processing. The characterization identifies the phases present, the degree of release of the ore, as well as the granulometric range in which the iron and quartz are concentrated.

If, in addition to the conventional information obtained, there is sufficient mineralogical information on the tailings, especially in relation to the presence of harmful minerals and the release of the minerals of interest, more accurate estimates 


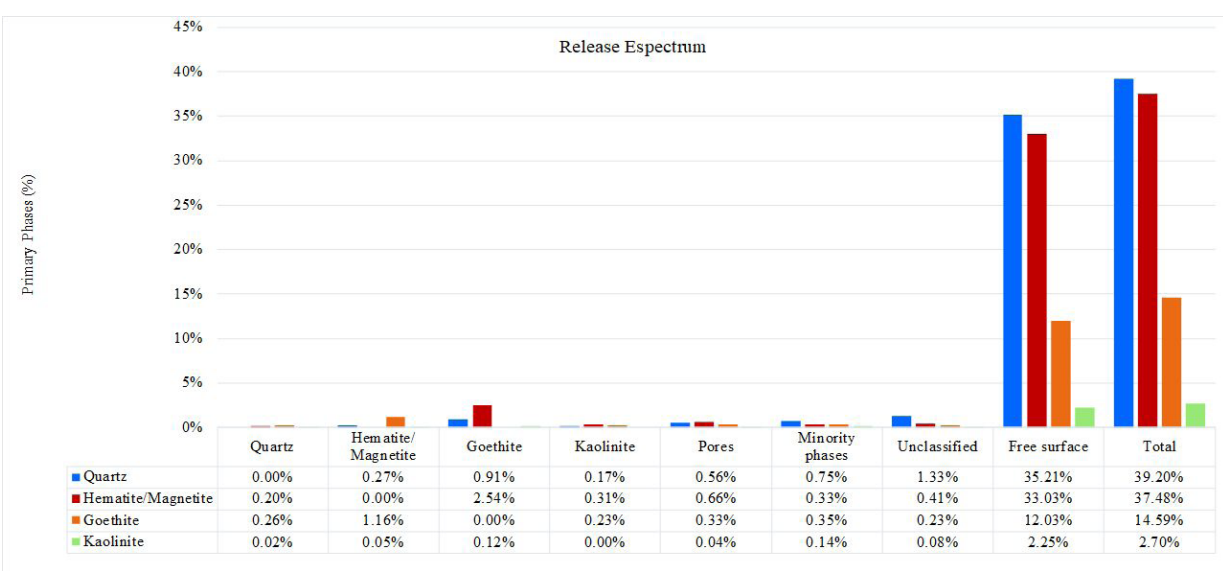

Figure 7. Spectrum of release by primary phases.

regarding the mass recovery of the concentration process become viable. The knowledge of the characteristics of the tailings offers the possibility of using alternative routes for the recovery of hematite, through magnetic concentration, associated with grinding, followed by flotation, as mentioned in the works ${ }^{11-13}$.

Another relevant study is presented by Roy ${ }^{14}$ who compares the conventional high intensity wet magnetic separation process (WHIMS) with the flake magnetic separation (FMS). As in the WHIMS magnetic separation process, the extent of the fluid's drag force exceeds the magnetic force exerted on the ultrafine particles, resulting in considerable loss in both iron content and mass recovery. Therefore, the FMS magnetic separation process is effective in the recovery of ultrafine particles, which could be applied to the material object of the present study, given its mineralogical characteristics, since the FMS process significantly increases the magnetic force on the ultrafine iron ore, which is in the form of hydrophobic flakes in the middle of a magnetic field.

Alternatives to processing models, and alteration of routes, usually come up against issues of operational practicality. In theory or in laboratory tests, the results for the concentration and recovery of the finer fraction of the ore can be achieved, but the reproduction of this operation on an industrial scale becomes impracticable, sometimes because it has a low recovery rate, sometimes because incorporate the milling step into the process, sometimes for the option of float or flocculate the ultrafine ore through the use of reagents, raising, directly or indirectly, operating costs. In such a way, such options must be well studied according to each type of ore and its morphology.

Thus, the knowledge of the particle morphology helps in the selection of the most adherent technologies to be used for each type of tailings and can also direct its use to other productive chains in the form of input to other productive chains, such as ceramic industry, civil construction.

The understanding of geological factors, the ability to relate and apply geological characteristics to industrial mineral processes, the understanding of advanced processing techniques, the ability to maximize the recovery rates of minerals of interest, and awareness of environmental issues, economic and social issues in mining are essential issues for sustainable development of the mining sector ${ }^{5}$.

\section{Conclusion}

It was concluded through characterization studies that the tailings are mainly composed of the phases of quartz $\left(\mathrm{SiO}_{2}\right)$ and hematite $\left(\mathrm{Fe}_{2} \mathrm{O}_{3}\right)$, presenting different proportions, and followed by the phases kaolinite $\left(\mathrm{Al}_{2} \mathrm{Si}_{2} \mathrm{O}_{5}(\mathrm{OH})_{4}\right)$, goethite $(\mathrm{FeO}(\mathrm{OH}))$ and gibbsite $\left(\mathrm{Al}(\mathrm{OH})_{3}\right)$. The chemical composition of the sample indicates that it has $32.29 \%$ iron, $47.92 \%$ silica, $2.76 \%$ alumina and ignition loss - PPI, equal to $2.14 \%$.

Microscopy studies revealed that hematite has small grains with varying shapes. Goethite, in turn, is associated with hematite, having very small grains with varied shapes. Gibbsite, hydrated aluminium hydroxide, together with other clay minerals, such as kaolinite, have very small grain sizes with varying shapes, while quartz has larger grains of varying and equiaxial sizes.

The X-ray and Rietveld diffraction analyzes reported that the sample contains quartz, in the proportion of $56.60 \%$ of the total sample, followed by hematite, $30.20 \%$, as the predominant phases, and as minority phases, kaolinite, $10.40 \%$, goethite, $2.70 \%$, and gibbsite, $0.20 \%$.

Through the results of the quantitative electron microscopy - QEM, it is confirmed that the hematite/magnetite phases can be classified as ultrafine and are in the range between $37 \mu \mathrm{m}$ and $6 \mu \mathrm{m}$, corresponding to $75.82 \%$ of the total of its particles, which suggests the possibility of recovery by classification in this particle size range. This is added to the fact that more than $88 \%$ of the hematite is released. It is worth mentioning that the quartz particles are thicker, having a more relevant start at $26 \mu \mathrm{m}$ or from $37 \mu \mathrm{m}$, thus defining a working cut range for the material.

The results obtained provide conditions for the improvement of the beneficiation process, such as the insertion of the magnetic concentration step after desliming by hydrocyclones, or the replacement of this step by magnetic concentration, such as the granulometric range with a high hematite content, for which, given the high degree of iron release, initially it would not be necessary to adopt the grinding step. It is 
necessary to take into account the possibility of insertion in the beneficiation process of the filtering stage of the tailings generated after the iron recovery stage, culminating thus in the consequent decrease in the sending of tailings to the dams.

In such a way, the information obtained by mineralogical characterization, X-ray diffraction, Rietveld, and quantitative electronic microscopy - QEM, denote the importance of an in-depth characterization, contributing to the development of a geometallurgical model in mining enterprises.

The optimization of the stages of processing, concentration and, subsequently, of the thickening and filtering of the tailings, through information about the chemical composition, the granulometric distribution, the phases present and the degree of release of these phases, are imperative information for the comprehensive use of tailings, for the conservation of nonrenewable and rapidly depleting natural resources and for the viability and sustainable development of mining.

\section{Acknowledgments}

The authors would like to thank the Gorceix Foundation (Ouro Preto), for the prompt assistance in carrying out the tests and for the unrestricted support in overcoming adversities, providing full conditions for carrying out the work. The authors would also like to thank the employees of the Gorceix Foundation, for their assistance and lessons, for sparing no effort in carrying out this work.

\section{References}

1. Quaresma LF. Publicação DNPM. 2001. https://www.gov.br/ anm/pt-br/centrais-de-conteudo/dnpm/paginas/balanco-mineral/ arquivos/balanco-mineral-brasileiro-2001-ferro/view

2. Jesus CAG. Publicação DNPM [Internet]. 2013 [cited 2013 Oct 26]. Available from: http://www.anm.gov.br/dnpm/publicacoes/ serie-estatisticas-e-economia-mineral/outras-publicacoes-1/31-2013-minerio-de-ferro-e-aco/view
3. Patra S, Pattanaik A, Venkatesh AS, Venugopal R. Mineralogical and chemical characterization of low-grade iron ore fines from Barsua Area, Eastern India with Implications on Beneficiation and Waste Utilization. J Geol Soc India. 2019;93:443-54.

4. IPEA: Instituto de Pesquisa Avançada. Diagnóstico dos resíduos sólidos da atividade de mineração de substâncias não energéticas. 2012. https://www.ipea.gov.br/portal/images/stories/PDFs/ relatoriopesquisa/120814_relatorio_atividade_mineracao.pdf

5. Gonçalves PCP. Geometalurgia: panorama da Aplicação no Setor Mínero-Metalúrgico (monografia de graduação). Universidade Federal de Ouro Preto; 2017. 90p.

6. Patra S, Pattanaik A, Rayasam V. Characterisation of low-grade Barsua iron ore fines and identification of possible beneficiation strategies. Canadian Metallurgical Quarterly. 2018;58(1):28-45.

7. Luz AB, Sampaio JA, França SCA. Tratamentos de minérios. 5. ed. Rio de Janeiro: Centro de Tecnologia Mineral; 2010. 960 p.

8. Araújo AC. Métodos de concentração. Apostila introdução ao tratamento de minérios. Belo Horizonte: UFMG; 2006. p. 108-150.

9. Pattanaik A, Patra S, Rayasam V. Selection of a viable upgradation strategy through physicochemical and mineralogical approach: a case study of low grade barsua iron ore fines

10. Gobbo LA. Aplicação da difração de raios X e método de Rietveld no estudo de Cimento Portland (Tese de doutorado). São Paulo: Universidade de São Paulo; 2009.

11. Chen L, Xiong D, Huang H. Pulsating high-gradient magnetic separation of fine hematite from tailings. Mining, Metallurgy \& Exploration. 2009;26(3):163-168p.

12. Kruger M, Naik S, Naudé N. Upgrade of SLon concentrate with the use of froth flotation on a typical African iron ore. Miner Process Extr Metall Rev. 2018;39(3):152-166p.

13. Silva JPM, Peres AEC, Isaac AC. Process route for low grade itabirites concentration: magnetic separation preceding flotation. Miner Process Extr Metall Rev. 2018;39(1):68-72p.

14. Roy S. Recovery improvement of fine magnetic particles by floc magnetic separation. Miner Process Extr Metall Rev. 2012;33(3):170-179p. 